\title{
Heterogeneous Distribution of Weedy Paspalum Species and Edaphic Variables in Turfgrass
}

\author{
Gerald M. Henry ${ }^{1}$ \\ Department of Plant and Soil Science, Texas Tech University, Box 42122, \\ Lubbock, TX 79409
}

\section{Michael G. Burton and Fred H. Yelverton \\ Department of Crop Science, North Carolina State University, Raleigh, NC 27695-7620}

Additional index words. Paspalum dilatatum, Paspalum notatum, spatial distribution, soil compaction, soil moisture, mowing height, elevation

\begin{abstract}
Dallisgrass (Paspalum dilatatum Poir.) and bahiagrass (Paspalum notatum Fluegge) are two of the most troublesome weed species in managed turfgrass. These rhizomatous, perennial grass species affect appearance, texture, and playability of turf in home lawns, golf courses, and athletic fields. The severity and prevalence of these problem species as well as the difficulty of achieving control with herbicide management alone invite the examination of their realized niches for clues to improved management tactics. The distribution of these species was evaluated in both fairways and roughs of three holes on each of two golf courses in North Carolina. Golf courses were selected based on the presence of both weed species. Individual plants were mapped using a highprecision global positioning system unit. This unit was also used to delineate between the rough and fairway height of cut as well as obtain elevation characteristics of each hole. Soil moisture and soil compaction estimates were obtained by sampling on a 9-m grid. Environmental characteristics used for $\chi^{2}$ analysis consisted of mowing height, soil compaction, soil moisture, and elevation. Data were subjected to $\chi^{2}$ analysis to determine if the existing distribution of Paspalum spp. differed from an expected random distribution across all environmental factors. Bahiagrass growth and distribution was more affected by mowing height than dallisgrass. Bahiagrass was predominantly distributed in the rough, whereas dallisgrass occurred at both mowing heights. Similar responses were observed for both species with regard to soil compaction. Higher plant density for both species was observed in moderately compacted soil $\left(40\right.$ to $\left.60 \mathrm{~N} \cdot \mathrm{m}^{-2}\right)$. Bahiagrass distribution was unaffected by soil moisture. Dallisgrass density was lower in areas with low volumetric soil water content (less than $27 \%$ ). Although different from an expected uniform distribution on all six holes, the elevation with the highest Paspalum spp. density varied across holes. Results suggest that it may be possible to disadvantage Paspalum spp. in competitive interactions with desirable species through the alteration of landscape attributes. Substrate selection during construction, aeration, and mowing height may help create a landscape that discourages Paspalum spp. infestation.
\end{abstract}

The perception of weed management changed from a systems approach to a reliance on chemical weed control soon after the introduction of herbicides (Mortensen et al., 2000). However, the onset of the "herbicide era" has yet to yield the eradication of a single weed species, whereas several new troublesome weed species have increased in

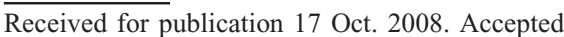
for publication 10 Dec. 2008 .

Texas Tech University manuscript no. T-4-601. We acknowledge the cooperation of Seth Williams for his technical assistance in this project. Appreciation is also extended to the Center for Turfgrass Environmental Research and Education for their financial support of this project. Also we thank Michael Gregory at Hidden Valley Golf Club and Reed Smith at Riverwood Golf Club for the use of their facilities.

${ }^{1}$ To whom reprint requests should be addressed; e-mail gerald.henry@ttu.edu. number (Altieri, 1991). Growing public concern and increasing occurrence of herbicide resistance have fueled the interest of several countries to propose herbicide use reductions. Knowledge of the interaction between weeds, their management, and the environment they exist in would better equip us for their control than overreliance on chemical control options (Mortensen et al., 1998a, 2000).

The development of integrated weed management strategies for managed ecosystems centers around habitat delineation of weed species (Cardina et al., 1997). The manipulation of environmental factors to improve crop growth conditions may be feasible through the correct identification of optimal environmental factors for weed growth and those unsuitable for desired crop growth while further reducing the amount of herbicide inputs (Johnson et al., 1997; Mortensen et al., 1998b). This is especially true for perennial weeds in natural ecosystems or reduced tillage systems, where plowing and cultivation are not management options.

Landscape attributes and weed species presence are spatially variable (Cardina et al., 1997; Johnson et al., 1995, 1996; Marshall, 1988; Thornton et al., 1990). In contrast, weed control tactics are often selected and implemented based on average field conditions. Investigating the spatial association of weed populations with edaphic and topographic features has the potential to benefit growers by reducing both input costs and the unneeded application of control tactics.

The introduction of new equipment and computer software used in georeferencing and managing data has made the study of spatial distribution of weeds with respect to their environment much easier (Dieleman and Mortensen, 1999; Prather and Callihan, 1993). A global positioning system (GPS) can be a valuable instrument for monitoring the spread and establishment of perennial weeds over time and may provide researchers with information about the effect of current management practices on specific perennial weeds (Webster and Cardina, 1997).

Several studies have examined the impact of cultural practices on the environment and the subsequent impact that the environment has on weed species distribution. Medlin et al. (2001) determined that sicklepod [Senna obtusifolia (L.) Irwin and Barnaby] infestation in agricultural fields was best predicted by organic matter content, phosphorus, potassium, and magnesium concentrations in the soil. Correlations between the presence of several broadleaf weeds with increased soil organic matter and lower topography were observed by Burton et al (2004, 2005) and Dieleman et al. (2000). Andreasen et al. (1991) correlated increasing common lambsquarter (Chenopodium album L.) populations with decreasing soil phosphorous and increasing common chickweed [Stellaria media (L.) Vill.] with increasing soil potassium.

To date, little information exists on the spatial dynamics of perennial turfgrass weeds. McElroy et al. (2005) correlated the presence of green kyllinga (Kyllinga brevifolia Rottb.) and false-green kyllinga (Kyllinga gracillima L.) on golf course fairways with increasing volumetric soil water content. Snaydon (1962) correlated increased white clover (Trifolium repens L.) density present in Festuca spp.Agrostis spp. grass swards with soil pH, calcium, and phosphorus.

In North Carolina, dallisgrass (Paspalum dilatatum Poir.) and bahiagrass (Paspalum notatum Fluegge) are two of the most prevalent and difficult to control weed species in turf. They are both rhizomatous, perennial grass species that readily invade golf course fairways and roughs. Few postemergence herbicide options exist for the effective, economical control of these weeds (Henry et al., 2007a; Hubbard et al., 2006; Ricker et al., 2005). These species are widely distributed throughout the state and anecdote 
suggests both tolerate droughty, sandy soils and moist, clayey soils. However, no known studies have examined the distribution of these species with respect to soil/environmental conditions or landscape features in managed turfgrass environments. Therefore, the objective of our research is to characterize the spatial distribution of naturally occurring populations of dallisgrass and bahiagrass and examine possible associations with mowing height, soil penetration resistance, volumetric soil water content, and elevation.

\section{Materials and Methods}

Ecological surveys were conducted on three golf course holes (rough and fairway) in the fall of 2004 at Hidden Valley Golf Club, Willow Springs, NC, and 2005 at Riverwood Golf Club, Clayton, NC. Golf courses were selected based on the presence of naturally occurring populations of dallisgrass and bahiagrass. Golf courses were considered experimental runs, whereas holes were considered replications within each run. The fairways and roughs of both golf courses are comprised of hybrid bermudagrass [Cynodon transvaalensis Burtt-Davy $\times$ C. dactylon (L.) Pers., cv. Tifway 419] mowed to a height of 1.3 and $6.4 \mathrm{~cm}$, respectively, and at a frequency of twice and once weekly, respectively. Fairways and roughs were supplied with supplemental irrigation on a need basis to promote vigorous and healthy turf. Chemical control of Paspalum spp. on either golf course was ineffective and consisted of spottreatment applications of glyphosate during the fall or multiple applications of monosodium methanearsonate throughout the growing season. The soil types present at Hidden Valley G. C. and Riverwood G. C. were predominantly a Wagram loamy sand (loamy, kaolinitic, thermic Arenic Kandiudults) and a Norfolk loamy sand (fine-loamy, kaolinitic, thermic Typic Kandiudults), respectively.

A real-time kinematic CMT Z33 DualFrequency GPS (CMT Inc., Corvallis, OR) unit was used to delineate mowing height (fairway versus rough), georeference Paspalum spp., and obtain elevation characteristics (meters above sea level) of each golf course hole. A differentially corrected Trimble AgGPS 132 (Trimble, Sunnyvale, CA) unit in combination with Farm Site Mate 7.13 software was used to superimpose a 9-m grid over each fairway and rough to sample for volumetric soil water content (soil moisture) and penetration resistance (soil compaction). The antenna was mounted just above the sensor to obtain submeter accuracy. Volumetric soil water content samples were recorded $3 \mathrm{~d}$ after an irrigation or rainfall event and were measured with a TH2O Theta Probe (Delta-T Devices, Ltd., Cambridge, U.K.) [measures percent volumetric soil water content in the top $10 \mathrm{~cm}$ of the soil profile $( \pm 1 \%)$ ] calibrated by soil specific gravimetric calibration. Soil penetration resistance samples were recorded $3 \mathrm{~d}$ after an irrigation or rainfall event and were measured with a Lang penetrometer (Lang Penetrometer Inc., Gulf Shores, AL) (estimates penetration resistance to a maximum depth of $12 \mathrm{~cm}$ in the soil profile). The Lang penetrometer was calibrated before use by testing it on soil columns of known penetration resistance. Two samples of each measurement were obtained at every reference location to ensure consistent instrument readings.

Categorical ranges were created for each landscape characteristic using Jenk's Natural Breaks Method with ArcMap 8.1 software (ESRI, Redlands, CA). Data from the 9-m grid sampling were interpolated using the Kriging method to create raster maps of each landscape characteristic for each golf course hole. A spherical semivariogram model with a variable radius type set to 12 was performed by the Kriging method. Kriging uses prior knowledge about the spatial distribution of a variable to predict values of said variable at unobserved points and turning the data into a raster map (Fig. 1). The number of each Paspalum spp. was determined in every categorical range of each landscape characteristic.

Data were subjected to $\chi^{2}$ analysis. $\chi^{2}$ analysis is calculated by finding the difference between each observed and expected frequency for each possible outcome, squar- ing them, dividing each by the expected frequency and taking the sum of the results:

$$
\chi^{2}=\sum_{i=1}^{n} \frac{\left(O_{i}-E_{i}\right)^{2}}{E_{i}}
$$

where:

$$
O_{i}=\text { an observed frequency; and }
$$$$
E_{i}=\text { an expected frequency. }
$$

$\chi^{2}$ analysis was used to test for goodness of fit to an expected, random distribution with respect to each landscape characteristic for each Paspalum spp. for each golf course hole (Table 1). A test of goodness of fit establishes whether an observed frequency distribution differs from an expected, random distribution. $\chi^{2}$ analysis was used to test the associations between categorical data at $P<0.05$. Preferred environments (categorical ranges) were reported for each species whose distribution differed from the expected distribution with respect to each landscape characteristic tested.

\section{Results and Discussion}

Mowing height. Spatial distribution of both Paspalum spp. on all six golf course holes was affected by mowing height $(P \leq$
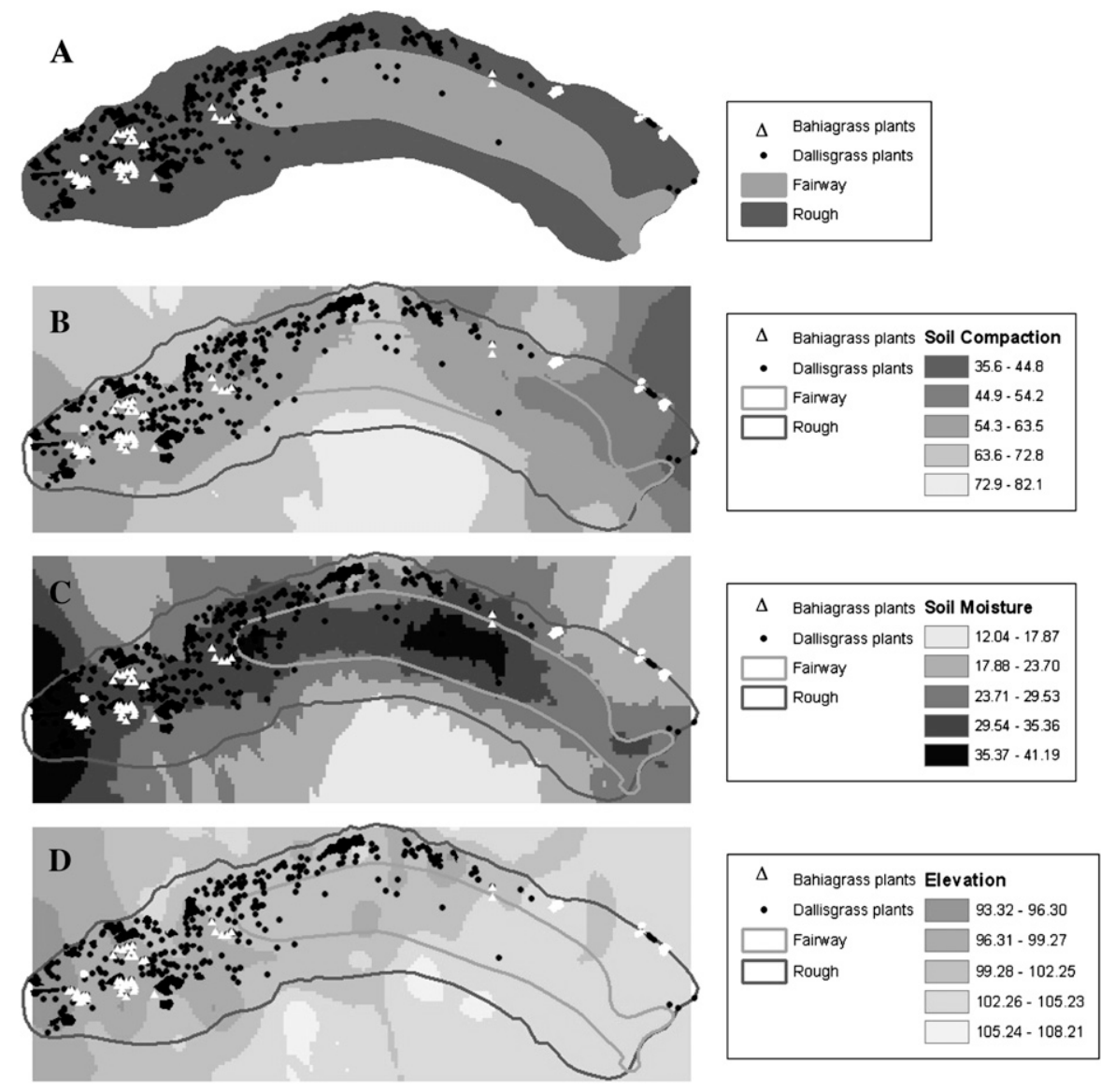

Fig. 1. Distribution of dallisgrass and bahiagrass on hole 14, Hidden Valley Golf Course, Willow Springs, $\mathrm{NC}$, with respect to (A) mowing height; (B) soil compaction $\left(\mathrm{N} \cdot \mathrm{m}^{-2}\right)$; (C) soil moisture (\%VWC); and (D) elevation (mas). 
Table 1. $\chi^{2}$ analysis of dallisgrass frequency with respect to soil compaction for hole 14 , Hidden Valley Golf Course, Willow Springs, NC.

\begin{tabular}{|c|c|c|c|c|c|}
\hline \multicolumn{6}{|c|}{ Soil compaction $\left(\mathrm{N} \cdot \mathrm{m}^{-2}\right)^{\mathrm{z}}$} \\
\hline Dallisgrass & $35.6-44.8^{y}$ & $44.9-54.2$ & $54.3-63.5$ & $63.6-72.8$ & $72.9-82.1$ \\
\hline Observed & 25 & 70 & 145 & 43 & 0 \\
\hline Expected & 56.6 & 56.6 & 56.6 & 56.6 & 56.6 \\
\hline Observed & 258 & 213 & 138 & 240 & 283 \\
\hline Expected & 226.4 & 226.4 & 226.4 & 226.4 & 226.4 \\
\hline
\end{tabular}

${ }^{2} \mathrm{~N} \cdot \mathrm{m}^{-2}=$ Newtons per meter squared

${ }^{y}$ Ranges were determined using Jenk's Natural Breaks Method.

Table 2. $\chi^{2}$ analysis of dallisgrass and bahiagrass spatial distribution with respect to landscape factors on six golf course holes in North Carolina.

\begin{tabular}{|c|c|c|c|c|c|}
\hline Variable & $\begin{array}{l}\text { Range of } \mathrm{N}^{\mathrm{z}} \\
\text { across holes }\end{array}$ & $\begin{array}{c}\text { Total N across } \\
\text { holes }\end{array}$ & $\mathrm{df}$ & $P$ value & $\begin{array}{c}\text { Apparent optimal } \\
\text { environment }\end{array}$ \\
\hline Mowing height & $(73-224)$ & $\begin{array}{l}928 \\
92 \text { - Bahiagr }\end{array}$ & S--- & All $\leq 0.001$ & Rough \\
\hline Soil compaction & $(73-224)$ & 928 & 4 & All $\leq 0.001$ & 45 to $64 \mathrm{~N} \cdot \mathrm{m}^{-2}$ \\
\hline Soil moisture & $(73-224)$ & 928 & 4 & $P \leq 0.05,5 \mathrm{NS}^{y}$ & Unaffected \\
\hline Elevation & $(73-224)$ & 928 & 4 & All $\leq 0.001$ & Volatile $^{\mathrm{x}}$ \\
\hline Mowing height & $(278-1043)$ & 2,481 & 1 & All $\leq 0.001$ & Rough \\
\hline Soil compaction & (278-1043) & 2,481 & 4 & $\mathrm{All} \leq 0.001$ & 45 to $64 \mathrm{~N} \cdot \mathrm{m}^{-2}$ \\
\hline Soil moisture & $(278-1043)$ & 2,481 & 4 & All $\leq 0.001$ & $\% \mathrm{VWC}>27 \%^{\mathrm{w}}$ \\
\hline Elevation & (278-1043) & 2,481 & 4 & All $\leq 0.001$ & Volatile \\
\hline
\end{tabular}

${ }^{\mathrm{z}} \mathrm{N}$ is number of observations.

${ }^{\text {y }}$ Soil moisture was significant at the $P \leq 0.05$ level on one hole and nonsignificant (NS) on the other five holes.

${ }^{\mathrm{x}}$ Although $\chi^{2}$ analysis indicated distributions that were significantly different from expected distributions in all cases, the pattern of distribution across elevation differed among holes and was not predictable.

wo $\% \mathrm{VWC}=$ percent volumetric water content.

0.001) (Table 2). Large patches of bahiagrass plants were observed in the rough of all holes, whereas few plants were recorded in the fairway. Henry et al. (2007b) observed that bahiagrass lateral spread and rhizome production was reduced $44 \%$ to $62 \%$ and $70 \%$ to $73 \%$, respectively, when mowed at $1.3 \mathrm{~cm}$ when compared with a nonmowed control. Lateral spread and rhizome production reductions were only $21 \%$ to $27 \%$ and $24 \%$ to $33 \%$, respectively, when bahiagrass was mowed at $7.6 \mathrm{~cm}$. Reductions in bahiagrass lateral spread and rhizome production in response to low mowing may be attributed to its morphology. Bahiagrass plants produce shallow, often-exposed rhizomes at the soil surface (McCarty et al., 2008). The increased frequency associated with close mowing and subsequent wear common to golf course fairways may cause extensive damage to bahiagrass rhizomes. The erect architecture of bahiagrass leaves and low shoot density create an open turf (Turgeon, 2008), making it very susceptible to competition from other turf and weed species. Therefore, when mowed at a low height of cut, reductions in lateral spread and rhizome production combined with competition from close mowingtolerant species like hybrid bermudagrass may create a habitat unsuitable for bahiagrass growth.

Dallisgrass plants were predominantly found in the rough, but several plants were also observed in the fairway. Plants in the fairway were typically smaller in diameter than those observed in the rough (visual assessment, data not shown). Henry et al. (2007b) reported reductions in dallisgrass lateral spread of $38 \%$ to $47 \%$ when compared with a nonmowed control regardless of mowing height $(7.6,5.2$, or $1.3 \mathrm{~cm})$. Reductions in dallisgrass rhizome production were $30 \%$ to $49 \%, 30 \%$, and $37 \%$ to $57 \%$ when mowed at $7.6,5.2$, and $1.3 \mathrm{~cm}$, respectively. Similar reductions in dallisgrass lateral spread and rhizome production in response to all mowing heights may be attributed to its morphology. Dallisgrass plants produce rhizomes deep beneath the soil surface. The protection of the soil may reduce potential damage resulting from low and frequent mowing and wear. Although dallisgrass plants were tolerant to close mowing, its bunch-type growth habit and direct competition with bermudagrass may make it difficult to spread throughout the fairway.

Soil compaction. Soil compaction was identified as a factor apparently affecting spatial distribution of both Paspalum spp. on all six golf course holes $(P \leq 0.001)$ (Table 2). Bahiagrass and dallisgrass were observed predominantly in areas with penetration resistance readings of 45 to $64 \mathrm{~N} \cdot \mathrm{m}^{-2}$. This range of soil compaction is considered moderate and areas of this magnitude consistently had dense, healthy bermudagrass cover.

Plant stress caused by soil compaction is often considered an indirect stress. Heavy and frequent traffic can alter the structure of the soil in a way that influences the aeration and moisture characteristics of the soil profile. Soil compaction can cause several physiological and morphological responses in plants, including reduced shoot and root growth, reduced nutrient and water uptake, and reduced tolerance to heat and drought stress (Turgeon, 2008).

Valoras et al. (1966) observed a reduction in top growth of common bermudagrass of $0.83 \mathrm{~g}$ dry weight to $0.40 \mathrm{~g}$ when grown in compacted soil conditions. Thurman and Pokorny (1969) also observed reductions in shoot growth of bermudagrass subjected to compaction. Letey et al. (1966) observed a reduction in root length of plants subjected to compaction when compared with plants grown in noncompacted soils. Although bermudagrass morphology is negatively affected by soil compaction, the dense, aggressive growth habit of bermudagrass may enable it to tolerate compaction better than dallisgrass and bahiagrass. Carrow et al. (2001) observed higher turf coverage for Cynodon spp. subjected to soil compaction and turfgrass wear than seashore paspalum (Paspalum vaginatum $\mathrm{Sw}$.), a turf-type grass in the same genus as dallisgrass and bahiagrass.

Soil moisture. Soil moisture was identified as a factor affecting spatial distribution of bahiagrass on one hole $(P<0.05)$ and not on the other five (Table 2). The small bahiagrass sampling size (73) associated with the one hole may have affected the resulting $\chi^{2}$ analysis. Van Wychen et al. (2004) observed wild oat (Avena fatua L.) growth and seed production regardless of field-scale heterogeneity of soil water use with or without competition from spring wheat (Triticum aestivum L.). Henry et al. (2006) suggested a possible correlation between bahiagrass success and low soil moisture content. Bahiagrass shoot and rhizome growth was greatest under droughtier soil conditions when grown on sandy loam soil regardless of whether grown in monoculture or in competition with hybrid bermudagrass $(P<0.0001)$. Survival of bahiagrass was unaffected by soil moisture regardless of soil type or whether grown in monoculture or in competition with hybrid bermudagrass $(P<0.0001)$.

The morphology of bahiagrass may provide insight into its ability to tolerate a wide range of soil moisture levels. Bahiagrass produces an extensive amount of adventitious roots that extend deep within the soil profile (Turgeon, 2008). A deep root system may allow bahiagrass to access soil moisture resources that would be difficult for other species to acquire. As previously mentioned, bahiagrass produces an abundance of shallow, often-exposed rhizomes at the soil surface (McCarty et al., 2008). The extension of rhizomes above the soil surface may allow for gas exchange in the presence of saturated soil conditions. Hybrid bermudagrass survival was greatly reduced in droughtier soil conditions regardless of soil type (Henry et al., 2006). Huang et al. (1997) reported a reduction in root growth of common bermudagrass [Cynodon dactylon (L.) Pers.] when the upper 20- and 40-cm layers of the soil profile were dried. Root dry weight of common bermudagrass only partially recovered to control levels after rewatering. Reductions 
in root growth and recovery during and after drought conditions may make bermudagrass less competitive with bahiagrass.

Dallisgrass spatial distribution was affected by soil moisture level on all six golf course holes $(P \leq 0.001)$ (Table 2$)$. Dallisgrass was predominantly observed in areas that had percent volumetric water content greater than 27\%. McElroy et al. (2005) reported that both green and false-green kyllinga were correlated with volumetric water levels greater than field capacity at five golf course locations. Henry et al. (2006) suggested a possible correlation between dallisgrass success in competition with hybrid bermudagrass and high soil moisture content. Maximum rhizome and shoot production was observed on more saturated soils regardless of soil type. Dallisgrass survival was reduced in droughtier soils. Rubio et al. (1995) and Rubio and Lavado (1999) observed a slight promotion of growth in $P$. dilatatum plants when exposed to flooding, whereas Loreti and Oesterheld (1996) only observed an increase in biomass accumulation in one of three biotypes in their research. Loreti and Oesterheld (1996) observed that drought reduced yield equally across three $P$. dilatatum biotypes.

The tolerance of dallisgrass to high soil moisture may be described by its growth characteristics and anatomical changes in response to flooding. Leaf extension rates and tiller height were also higher in flooded $P$. dilatatum plants (Insausti et al., 2001; Loreti and Oesterheld, 1996; Rubio et al., 1995). Increasing plant height is a flooding response that allows avoidance of leaf submergence (Laan and Blom, 1990; Oesterheld and McNaughton, 1991; Van der Sman et al., 1993). P. dilatatum was observed to produce aerotropic and adventitious roots that grow upward to oxygenated areas (Rubio et al., 1995), thus supplying oxygen to the roots (Glinski and Stepniewski, 1985; Kozlowski, 1984). Several researchers also observed an increase in root aerenchyma tissue of $P$. dilatatum in response to flooding (Loreti and Oesterheld, 1996; Rubio et al., 1995; Vasellati et al., 2001). Increased aerenchyma tissue is a common adaptive response of plants to soil anoxia (Jackson and Armstrong, 1999; Jackson and Drew, 1984; Justin and Armstrong, 1987). Scifres and Mutz (1975) reported that longtom (Paspalum lividum Torr.) initially stabilized areas as free-standing water withdrew followed by common bermudagrass after extended fresh water inundation for several years in a coastal rangeland. The presence of common bermudagrass immediately after the removal of free-standing water may confirm its ability to tolerate saturated soil environments. Therefore, in the presence of saturated soil conditions, dallisgrass and hybrid bermudagrass may be competitive with one another.

Elevation. Although different from an expected uniform distribution on all six holes, the elevation with the highest Paspalum spp. density varied across holes. Van Wychen et al. (2004) reported that elevation correlated with existing wild oat patches in individual fields but was not consistent with wild oat patches in all three fields. Elevation leads to edaphic heterogeneity along elevation gradients by influencing spatial patterning of edaphic variables (Beckett and Webster, 1971; Brubaker et al., 1993; Day et al., 1987; Miller et al., 1988). McElroy et al. (2005) hypothesized that the influence of elevation on edaphic variables led to a lack of significant correlations. The effect of elevation on edaphic variables was significant at all site locations, but results varied across sites.

$\chi^{2}$ analysis is limited by its inability to examine interactions between edaphic variables on species distribution. Therefore, ignoring relationships among elevation, soil moisture, soil compaction, and mowing height may have complicated attempts to associate edaphic variables with the presence of dallisgrass and bahiagrass. However, results suggest that high mowing height is a major contributor to dallisgrass and bahiagrass proliferation and is probably related to decreased turfgrass competitiveness. Therefore, the most conceivable integrated weed management strategy for dallisgrass and bahiagrass would be to decrease the mowing height in the rough to discourage Paspalum spp. growth and encourage the competitiveness of bermudagrass. More frequent mowing in the rough may also reduce seedhead production and further improve long-term management of these weeds. High soil moisture may also lead to increased infestation of Paspalum spp. and is probably related to decreased turfgrass growth. Thus, the most plausible management strategy for dallisgrass and bahiagrass would be to maintain adequate soil moisture but avoid overirrigation. Installation of subsurface drainage may reduce standing water in frequently inundated areas and further improve long-term control of these weeds. Low soil moisture may lead to increased infestation of bahiagrass and is probably related to decreased turfgrass growth or plant death. Maintaining adequate soil moisture, wetting agent application, and amending the soil to increase waterholding capacity may aid in the control of bahiagrass in situations of low soil moisture.

Weed spatial distribution and habitat suitability will differ for other species. However, researchers should proceed with caution when extrapolating correlative results between soil properties and weed distributions, especially for weeds with a wide geographic distribution. The effects of fecundity, seed dispersal, management, and habitat need to be considered when predicting weed population distributions across turfgrass environments. More importantly, the potential influence of edaphic conditions on weed management along elevation gradients should be among the concerns of golf course designers; such forethought could pre-empt potential edaphic heterogeneity (such as poor drainage) and aid in the reduction of habitats favorable to weed invasion.

\section{Literature Cited}

Altieri, M.A. 1991. Increasing biodiversity to improve insect pest management in agroecosystems. p. 165-182. In: Hawksworth, D.L. (ed.). The biodiversity of microorganisms and invertebrates: Its role in sustainable agriculture. Proc. First Workshop on the Ecological Foundations of Sustainable Agriculture (WEFSA 1). CAB International, Wallingford, UK.

Andreasen, C., J.C. Streibig, and H. Haas. 1991. Soil properties affecting the distribution of 37 weed species in Danish fields. Weed Res. 31:181-187.

Beckett, P.H.T. and R. Webster. 1971. Soil variability: A review. Soils and Fertilizers 34:1-15.

Brubaker, S.C., A.J. Jones, D.T. Lewis, and K. Frank. 1993. Soil properties associated with landscape position. Soil Sci. Soc. Amer. J. 57: 235-239.

Burton, M.G., D.A. Mortensen, and D.B. Marx. 2005. Environmental characteristics affecting Helianthus annuus distribution in a maize production system. Agr. Eco. and Environ. 111: 30-40.

Burton, M.G., D.A. Mortensen, D.B. Marx, and J.L. Lindquist. 2004. Factors affecting the realized niche of common sunflower (Helianthus annuus) in ridge-tillage corn. Weed Sci. 52:779-787

Cardina, J., G.A. Johnson, and D.H. Sparrow. 1997. The nature and consequence of weed spatial distribution. Weed Sci. 45:364-373.

Carrow, R.N., R.R. Duncan, J.E. Worley, and R.C. Shearman. 2001. Turfgrass traffic (soil compaction plus wear) simulator: Response of Paspalum vaginatum and Cynodon spp. Intl. Turf. Soc. Res. J. 9:253-258.

Day, L.D., M.E. Collins, and N.E. Washer. 1987. Landscape position and particle-size effects on soil phosphorus distributions. Soil Sci. Soc. Amer. J. 51:1547-1553.

Dieleman, J.A. and D.A. Mortensen. 1999. Characterizing the spatial pattern of Abutilon theophrasti seedling patches. Weed Res. 39:455-467.

Dieleman, J.A., D.A. Mortensen, D.D. Buhler, C.A. Cambardella, and T.B. Moorman. 2000. Identifying associations among site properties and weed species abundance. I. Multivariate analysis. Weed Sci. 48:567-575.

Glinski, J. and W. Stepniewski. 1985. Soil aeration and its role for plants. CRC Press, Boca Raton, FL.

Henry, G.M., M.G. Burton, and F.H. Yelverton. 2006. Response of dallisgrass and bahiagrass along a soil moisture gradient. In: Proc. Northeastern Weed Sci. Soc 60:11.

Henry, G.M., M.G. Burton, and F.H. Yelverton. 2007a. Dallisgrass (Paspalum dilatatum Poir.) control with foramsulfuron in bermudagrass turf. Weed Technol. 21:759-762.

Henry, G., M. Burton, and F. Yelverton. $2007 \mathrm{~b}$. Effect of mowing on lateral spread and rhizome growth of troublesome Paspalum species. Weed Sci. 55:486-490.

Huang, B., R.R. Duncan, and R.N. Carrow. 1997. Drought-resistance mechanisms of seven warm-season turfgrasses under surface soil drying: II. Root aspects. Crop Sci. 37:18631869.

Hubbard, L.R., A.G. Estes, and L.B. McCarty. 2006. Revolver and MSMA for dallisgrass control in bermudagrass turf. In: Proc. Southern Weed Sci. Soc 59:128.

Insausti, P., A.A. Grimoldi, E.J. Chaneton, and V. Vasellati. 2001. Flooding induces a suite of adaptive plastic responses in the grass Paspalum dilatatum. New Phytol. 152:291-299.

Jackson, M.B. and W. Armstrong. 1999. Formation of aerenchyma and the processes of plant 
ventilation in relation to soil flooding and submergence. Plant Biol. 1:274-287.

Jackson, M.B. and M. Drew. 1984. Effects of flooding on growth and metabolism of herbaceous plants. p. 47-128. In: Kozlowski, T.T. (ed.). Flooding and plant growth. Academic Press Inc., London, UK.

Johnson, G.A., J. Cardina, and D.A. Mortensen. 1997. Site-specific weed management: Current and future directions, p. 131-148. In: Pierce, F.J. and E.J. Sadler (eds.). The state of sitespecific management for agriculture. ASACSSA-SSSA, Madison, WI.

Johnson, G.A., D.A. Mortensen, and C.A. Gotway. 1996. Spatial and temporal analysis of weed seedling populations using geostatistics. Weed Sci. 44:704-710.

Johnson, G.A., D.A. Mortensen, and A.R. Martin. 1995. A simulation of herbicide use based on weed spatial distribution. Weed Res. 35:197-205.

Justin, S.H.F. and W. Armstrong. 1987. The anatomical characteristics of roots and plant response to soil flooding. New Phytol. 106:465-495.

Kozlowski, T.T. 1984. Plant responses to flooding. Bioscience 34:162-167.

Laan, P. and C.W.P.M. Blom. 1990. Growth and survival responses of Rumex species to flooded and submerged conditions. The importance of shoot elongation, underwater photosynthesis and reserve carbohydrates. J. Expt. Bot. 228: 775-783.

Letey, J., W.C. Morgan, S.T. Richards, and N. Valoras. 1966. Physical soil amendments, soil compaction, irrigation, and wetting agents in turfgrass amendment. III. Effects on oxygen diffusion rates and root growth. Agron. J. 58:531-535.

Loreti, J. and M. Oesterheld. 1996. Intraspecific variation in the resistance to flooding and drought in populations of Paspalum dilatatum from different topographic positions. Oecologia 108:279-284.

Marshall, E.J.P. 1988. Field-scale estimates of grass weed populations in arable land. Weed Res. 28:191-198.
McCarty, L.B., J.W. Everest, D.W. Hall, T.R. Murphy, and F.H. Yelverton. 2008. Color atlas of turfgrass weeds. 2nd ed. Ann Arbor Press, Chelsea, MI.

McElroy, J.S., F.H. Yelverton, M.G. Burton, and C. Brownie. 2005. Habitat delineation of green and false-green kyllinga in turfgrass systems and interrelationship of elevation and edaphic factors. Weed Sci. 53:620-630.

Medlin, C.R., D.R. Shaw, M.S. Cox, P.D. Gerard, M.J. Abshire, and M.C. Wardlaw III 2001. Using soil parameters to predict weed infestations in soybean. Weed Sci. 49:367-374.

Miller, M.P., M.J. Singer, and D.R. Nielsen. 1988. Spatial variability of wheat yield and soil properties on complex hills. Soil Sci. Soc. Amer. J. 52:1133-1141.

Mortensen, D.A., L. Bastians, and M. Sattin. 2000. The role of ecology in the development of weed management systems: An outlook. Weed Res. 40:49-62.

Mortensen, D.A., L.G. Higley, J.A. Dieleman, J.L. Lindquist, and D.L. Holshouser. 1998a. Ecological principles underlying integrated weed management systems. In: Proc. Weed Science Society of America 38:42.

Mortensen, D.A., J.A. Dieleman, and G.A. Johnson. 1998b. Weed spatial variation and weed management. p. 293-310. In: Hatfield, J.L., D.D. Buhler, and B.A. Stewardt (eds.). Integrated weed and soil management. Sleeping Bear, Ann Arbor, MI

Oesterheld, M. and S.J. McNaughton. 1991. Interactive effect of flooding and grazing on the growth of Serengeti grasses. Oecologia $88: 153-156$.

Prather, T.S. and R.H. Callihan. 1993. Weed eradication using geographic information systems. Weed Technol. 7:265-269.

Ricker, D.B., J.B. Willis, D.S. McCall, and S.D. Askew. 2005. Dallisgrass control with foramsulfuron. In: Proc. Southern Weed Sci. Soc. $58: 125$.

Rubio, G., G. Casasola, and R.S. Lavado. 1995. Adaptations and biomass production of two grasses in response to waterlogging and soil nutrient enrichment. Oecologia 102:102105.

Rubio, G. and R.S. Lavado. 1999. Acquisition and allocation of resources in two waterloggingtolerant grasses. New Phytol. 143:539-546.

Scifres, C.J. and J.L. Mutz. 1975. Secondary succession following extended inundation of Texas coastal rangeland. J. Range Mngmt. 28:279-282.

Snaydon, R.W. 1962. Micro-distribution of Trifolium repens $\mathrm{L}$. and its relation to soil factors. J. Ecol. 50:133-143.

Thornton, P.K., R.H. Fawcett, J.B. Dent, and T.J. Perkins. 1990. Spatial weed distribution and economic thresholds for weed control. Crop Prot. 9:337-342.

Thurman, P.C. and F.A. Pokorny. 1969. The relationship of several amended soils and compaction rates on vegetative growth, root development and cold resistance of Tifgreen bermudagrass. J. Amer. Soc. Hort. Sci. 94:463465.

Turgeon, A.J. 2008. Turfgrass management. 8th Ed. Prentice Hall, Upper Saddle River, NJ.

Valoras, N., W.C. Morgan, and J. Letey. 1966 Physical soil amendments, soil compaction, irrigation, and wetting agents in turfgrass management. II. Effects on top growth, salinity, and minerals in the tissue. Agron. J. 58:528-531.

Van der Sman, A.J.M., C.W.P.M. Blom, and G.W.M. Barendse. 1993. Flooding resistance and shoot elongation in relation to developmental stage and environmental condition in Rumex maritimus L. and Rumex palustris $\mathrm{Sm}$. New Phytol. 125:73-84.

Van Wychen, L.R., B.D. Maxwell, A.J. Bussan, P.R. Miller, and E.C. Luschei. 2004. Wild oat (Avena fatua) habitat and water use in cereal grain cropping systems. Weed Sci. 52:352-358.

Vasellati, V., M. Oesterheld, D. Medan, and J. Loreti. 2001. Effects of flooding and drought on the anatomy of Paspalum dilatatum. Ann. Bot. (Lond.) 88:355-360.

Webster, T.M. and J. Cardina. 1997. Accuracy of a global positioning system (GPS) for weed mapping. Weed Technol. 11:782-786. 